\title{
Value of Meditation in Education : A Krishnamurtian perspective
}

\author{
Simmin Bawa ${ }^{1}$ \\ ${ }^{1}$ Assistant Professor and Head, Department of Philosophy, Jaihind College, Mumbai. \\ E-mail-simminbawa@gmail.com
}

\begin{abstract}
Meditation, as we know it, is not an integral part of education under contemporary academic curriculum; however, the Vedic concept of Ashrama Dharma suggests its practice (in different degrees) throughout the four stages of man's life. The common belief, that the value of meditation resides in a religious and spiritual context, robs it of its place in education. The purpose of our current education system is to make human beings conform to and fit into society and culture, to fit into the stream of social and economic activity; for most mainstream educationists there seems to be no apparent connection between 'classroom meditation' and education. J. Krishnamurti's perspective on meditation stirs the human mind with a number of questions, interrogating and trying to build a possible connection between the two. The article proposes to look at Krishnamurti's perspective on the connection between the value of meditation and education by examining his ideas on the following aspects:

(i) the function, method and significance of education; (ii) the proposal that 'classroom meditation' is an integral component of transformative education; and (iii) how 'classroom meditation' leads to a valuable wholeness and totality of life. The Krishnamurtian meditation when made an integral part of academic curricula can lead to the natural flowering of values which has potential advantages at different levels, viz., individual, family, society, community and the globe.
\end{abstract}

Key words : Krishnamurti, meditation, education, students, value, mind, silence, astachal.

\section{INTRODUCTION}

Ancient Indian system of education spearheaded an all-round, valueoriented and holistic development of the individual. This included a perfect harmony between the body, mind and soul. Contemporary education system seems to revolve more around economic considerations and human values hold a secondary position. Education tends to be a process of training whereby individuals in society are enabled to embody progressively those values, which we in our highest thought and aspiration come to regard as something most desirable. Thus education seems to be a normative endeavour. Values as understood in the context of educational philosophy refers to those desirable ideals and goals which are intrinsic in themselves and which, when achieved or 
attempted, evoke a deep sense of fulfilment to one or many or all parts of what we consider to be the highest elements of our human nature.

Krishnamurti believes that conventional education makes independent thinking difficult as he supposes that conformity leads to mediocrity. The same curriculum (with minor changes) is used year after year, students are expected to reproduce the data and sadly specific interest of students is overlooked. Their creativity is not given a horizon. This traditional process of education suffocates students, blocks creativity, puts an end to spontaneity, breeds fear and fear blocks the intelligent understanding of life. Human intelligence is not merely the capacity to reason but rather is more potent to perceive 'what is'; to discriminate and understand truth from falsehood, but this is being destroyed by perpetual emphasis on authority, acceptance and imitation. The question that now arises is: in all this, what part has meditation to play in the process of education especially in classrooms ? [1]

Before understanding what is meditation for Krishnamurti, let's see what it's not for him. 1) meditation is not a movement from one reality to another i.e., a movement from the ordinary worldly attitude of life to something noble and elevating; 2) it is not an escape from the world; it is not an isolating self-enclosing activity; 3 ) and finally, not a mind controlling technique.

\section{KRISHNAMURTI'S CONCEPT AND METHOD OF MEDITATION}

Meditation for Krishnamurti is a non-denominational term. It is actually seeing 'what is'; the comprehension of the world and its ways. Krishnamurti builds a deep link between meditation and thinking. He asserts that in meditation, it is the quietness of the body which is not enforced or sought after. The example he gives is of observing a tree blowing in the wind and the same tree in the evening when the sun has set which is now quiet. In the same way, he expects the body to be quiet naturally and normally. All this implies an enquiring mind devoid of assumptions of starting from a motive or seeking a conclusion. So he contends that meditation is the unfolding of the mind. Through the perception of the mind there should arise a seeing which is without any restraints, without any backgrounds and thus an endless emptiness in which to see is the goal. For this process, Krishnamurti requires a mind that is absolutely quiet and still. He gives example of observation of a bird. To observe it prudently one must be very quiet otherwise at the least movement the bird flies away. Therefore, the whole of one's body must be quiet, relaxed and sensitive to observe and be attentive. In meditation, the observer and his scale of observation are not two different things; in fact the scale of observation is actually the observer [2].

Krishnamurti proclaims that meditation implies the whole of life and not just the technical, monastic, or scholastic life, but total life and to apprehend and communicate this totality, there must be a certain seeing of it. This seeing requires that the mind in a spaceless and timeless state. Meditation is a way of putting aside altogether everything that man has conceived of himself and of the world and the environment around him. The mind must perceive and witness the whole picture at once. In meditation which is nothing but observation of the mind and its modes, one has to find out whether there is an end to knowledge and so to freedom from the known or in other words, the accumulated past with the memory of it. If we accept meditation as a continuation of knowledge, then there arise a continuation of everything that man has accumulated; which means then there is no freedom. Krishnamurti avows that humans realise there is freedom only when there is total understanding of the function of knowledge and therefore freedom from the known. In meditation, what is important is 
not controlling thoughts, but understanding its origin. In Sigmund Freud's psychoanalysis too the origin of the thought was important to reach the root of problems.

Krishnamurti maintains that total revolution within an individual is possible only through a psychological revolution and this revolution is possible only through the medium of meditation. Meditation gives rise to an intelligent revolt which is not a reaction. It comes with self-knowledge through the awareness of one's own thoughts and feelings. One needs to face experiences as they come and keep intelligence highly awakened. This highly awakened intelligence is intuition, which is the only true guide in life. Krishnamurti's aim is to bring about a radical change within human nature. He proposes a Vedantic idea that one's self is the world and the world is oneself i.e. I am world and world is me. If this realization dawns on man then Krishnamurti believes it will lead to a radical revolution; and this change will inevitably effect the world. This is because we are a part of the world; any change within me will lead to a change worldwide [3].

\section{WHAT IS THE VALUE OF CLASSROOM MEDITATION TO STUDENTS ?}

In the process of education, it is necessary for the students to observe and think with an open mind. The mind should be subtle and still. Student's bodies should be responsive and sensitive. But above all the student should be eager. Meditation helps the mind and body to be calm and quiet. The quiet mind can pay attention on detailing. Krishnamurti thinks that intelligence comes into being when the brain discovers its fallibility. It is the process of meditation that helps man discover what he is and is not capable of. Krishnamurti wants students to question their beliefs and consider if they are dogmas or are a result of free thinking. Meditation helps the mind to sort such conflict in an amicable manner. Krishnamurti wants the brain to be active and thoughts to be new. This fresh brain is first-hand, original, innovative and neoteric. Intelligence cannot function when the old brain is active. Formal education can train the mind about the past techniques and occurrences and expect that the same is memorized and repeated. But Krishnamurti is of the opinion that a mind that has merely been trained is the continuation of the past can never discover the new. Even awareness that limitation belongs to an old realm is intelligence according to Krishnamurti. When such an intelligence is developed, and constantly renewed can the new boundless horizons of various dimensions operate through it. This will give rise to creativity and variety in problem-solving techniques and innovation that will globally benefit mankind [4].

Krishnamurti emphasizes on academics for students but he insists that learning should not be restricted to just academics. Classroom meditation if made a part of the curriculum, can help students to learn: [5]

a) How to 'look' at an object. This looking at objects is from different points of views without limitations.

b) How to 'listen' carefully, attentively and not just to what is being said but also the unsaid sounds. He wanted students to be sensitive and listen to the sounds produced by different creatures of nature including trees, birds, animals, wind, flowing water, etc.

c) In-depth thinking about things. Thinking can be very analytical but what is important is to distinguish whether what is being said is true or false, how helpful can the fact be, how and where it can be used, etc. 
d) Meditation will help students observe and understand their own self-projected values. Students can recognize for themselves the conditioning factors that have influenced them in the past and that can influence them in future.

e) Moreover, students learn to see themselves clearly in a holistic manner and not in fragments. Students will assimilate themselves which will aid in inter-personal relationships with others and also their surrounding environment besides themselves.

Meditation can sharpen the mind to think anew and from different aspects so that greater development of the individual, society and the globe at large is possible. It seems like Krishnamurti endeavours to encourage schools to repackage curriculums and make classroom meditation an integral component as the only aim of education should not be to churn out professionals. Professions take up our whole lives and towards the beginning of retirement we turn to meditation which we undertake as a pass time or again as an age old dogma which claims meditation will lead to salvation. Krishnamurti encourages us to meditate every moment of our life by continuously or choicelessly observing out thoughts and feelings. This will develop a constant contemplative attitude of mind [6].

Classroom meditation when made a part of the regular curriculum can help shape a set of new values which will transform the future of individuals by making them aware of the horizon of freedom, limitless creativity and blissful peace. At the same time, students will realize the unpleasant effects of conformity and competition that exists consciously or unconsciously within individuals, society and create harmony in the world we live in.

Students having studied at Krishnamurti schools like Rishi valley and Sahyadri, said that daily meditation was an integral part of their academic curriculum. They had to observe silence for a minute before morning assembly started, after it ended, before meals, and many more times in a single day. These moments of silence were to observe their thoughts and this is what Krishnamurti means by meditation. Besides the above, daily they were taken for a duration of 20 minutes to the nearby hill top in simple (preferably white and loose) clothes where they maintained complete silence. This activity was known as 'astachal' and it gave students time for quiet reflection. Students had the freedom to sit wherever they wanted to even on branches of trees. In these 20 minutes of silence, no instructions were given. They had the freedom to do the following: [7]

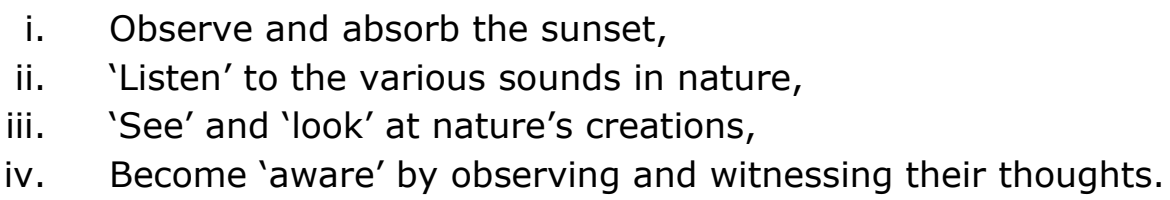

Besides the above, few students wrote poems and composed songs, penned their thoughts in personal diaries, wrote stories, etc. This practice made them feel calmer, aware of their thought processes, sensitive to the environment and also appreciate beauty in nature. They claimed it was a very creative and productive time which they zealously looked forward to. But what is most important is that all alleged it helped them immensely in academics by way of being able to analyse well, think differently and much more. They also felt more creative and this creative thought was described as 'boundless' by them. Silence had become an integral and unconscious part of their student life. Many alumnus claimed to continue the Krishnamurtian meditation as an essential and blissful part of their daily lives [8]. 


\section{CONCLUSION}

Schools, colleges, universities and educational institutions can consider the above benefits of incorporating meditation in their curriculums and assess for themselves whether the quality of teaching-learning experience is enhanced or not. In case, educational institutions feel that such an activity takes up teaching hours and hence not viable then meditation can be encouraged as an extra-curricular activity or an add on programme. Meditation will make students see and experience the value of life in its totality. Ultimately, the gift of silence, calmness and tranquillity should be deeply respected and experienced in daily life even after formal classroom education ends.

\section{REFERENCES AND RECOMMENDED FURTHER READING}

1. Krishnamurti J. Beginnings of Learning. London: Penguin Books, 1978.

2. Krishnamurti J. Education and the significance of life. New York: Harper and Row, 1953.

3. Krishnamurti J. Freedom From the Known. Chennai: Krishnamurti Foundation of India, 1999.

4. Krishnamurti J. On Education. Chennai: Krishnamurti Foundation of India, 1998.

5. Krishnamurti J. The Awakening of Intelligence. London: Penguin Books, 1973.

6. Krishnamurti J. The Revolution from Within. California: Krishnamurti Foundation of India, 1999.

7. Mehta R. J. Krishnamurti and the Nameless Experience. Delhi: Motilal Banarsidass Publishers Private Limited, 1989.

8. Joshi K. Philosophy of Value-Oriented Education - Theory and Practice. New Delhi: Indian Council of Philosophical Research, 2002.

Acknowledgements - Nil.

Conflict of Interest - Nil.

Funding - Nil. 